\title{
Morphine, a potential inhibitor of myeloperoxidase activity
}

\author{
P. Nyssen ${ }^{\mathrm{a}, *}$, A. Mouithys-Mickalad ${ }^{\mathrm{b}}$, G. Minguet ${ }^{\mathrm{c}}$, E. Sauvage $^{\mathrm{d}}$, J. Wouters $^{\mathrm{e}}$, T. Franck ${ }^{\mathrm{b}}$, \\ M. Hoebeke ${ }^{a}$
}

a Biomedical Spectroscopy Laboratory, Department of Physics, CESAM, ULiège, Sart-Tilman, B-4000 Liège, Belgium

${ }^{\mathrm{b}}$ CORD, Department of Chemistry, CIRM, ULiège, Sart-Tilman, B-4000 Liège, Belgium

${ }^{\mathrm{c}}$ Department of Anesthesia and Intensive Care Medicine, CHU of Liège, ULiège, Sart-Tilman, B-4000, Liège, Belgium

d Laboratory of Crystallography, Center for Protein Engineering-InBioS, ULiège, Sart-Tilman, B-4000, Liège, Belgium

e Laboratoire de Chimie Biologique Structurale, UNamur, B-5000 Namur, Belgium

\section{A R T I C L E IN F O}

\section{Keywords:}

Morphine

Myeloperoxidase

Inhibitor

Docking

EPR

SIEFED

\begin{abstract}
A B S T R A C T
Morphine is an opioid alkaloid commonly used in clinical practice for its analgesic properties. The phenolic hydroxyl group of that phenanthrene derivative is pivotal for binding to opioid receptors but it may also be responsible for the antioxidant behavior of morphine reported in several in vitro experiments. In this study, we assessed the effect of morphine on myeloperoxidase (MPO), a hemic enzyme from azurophilic granules of polymorphonuclear neutrophils involved in the production of cytotoxic and microbicidal reactive oxidants during inflammatory response. Specific immunological extraction followed by enzyme detection (SIEFED) and molecular modeling (docking) were performed to study the potential anti-catalytic action of morphine on MPO in comparison with the inhibitory effects of reference antioxidant molecules quercetin, gallic acid and ascorbic acid. The reducing action of morphine on the MPO peroxidase cycle has been investigated using electron paramagnetic resonance (EPR) and UV-visible absorption spectroscopy. Morphine acted as a reducing substrate in the peroxidase cycle of MPO and therefore protected the enzyme against the suicide action of its natural substrate, hydrogen peroxide. The SIEFED experiments associated with the docking study, further demonstrated a lack of strong and sustained anti-catalytic activity of morphine. In summary, from the results of this study, it appears that morphine acts as a weak and reversible inhibitor of MPO that may nonetheless contribute to immunomodulatory and antioxidant effects of this opioid analgesic in vivo.
\end{abstract}

\section{Introduction}

Inflammation is a complex physiological phenomenon involving cellular, enzymatic and chemical mechanisms to remove damaged host structures, prevent invasion by various infectious agents or tumor cells and prepare for future tissue repair and regeneration. During this phenomenon, polymorphonuclear leukocytes (PMNs) play an important role by producing reactive oxygen species (ROS) like superoxide anion, hydroxyl radical or singlet oxygen. PMNs also release myeloperoxidase (MPO), a pro-oxidant hemic enzyme belonging to their intricate oxidative system. [1-5] MPO is a peroxidase, composed of two symmetrical hemi-enzymes, each owns a heme constituted of a porphyrin and an iron atom in the ferric state. This enzyme has two main activities: chlorination and peroxidase, closely related to the production of ROS. As a peroxidase, MPO catalyzes the oxidation of substrates, acting as electron donors, via hydrogen peroxide, its natural substrate [6-9].

$$
\mathrm{AH}_{2}+\mathrm{H}_{2} \mathrm{O}_{2} \rightarrow A^{-}+2 \mathrm{H}_{2} \mathrm{O}
$$

This peroxidase action takes place in three steps:

$$
\begin{aligned}
& M P O-\mathrm{Fe}(I I I)+\mathrm{H}_{2} \mathrm{O}_{2} \rightarrow M P O^{+\cdot}-\mathrm{Fe}(\mathrm{IV})=\mathrm{O}+\mathrm{H}_{2} \mathrm{O} \\
& M P O^{+\cdot}-\mathrm{Fe}(I V)=\mathrm{O}+\mathrm{AH}_{2} \rightarrow \mathrm{MPO}-\mathrm{Fe}(I V)=\mathrm{O}+\mathrm{AH}+\mathrm{H}^{+} \\
& M P O-\mathrm{Fe}(\mathrm{IV})=\mathrm{O}+\mathrm{AH}_{2} \rightarrow \mathrm{MPO}-\mathrm{Fe}(\mathrm{III})+\mathrm{AH}+\mathrm{H}_{2} \mathrm{O}
\end{aligned}
$$

During the first step, the resting state of the enzyme is oxidized to its oxoferryl $\pi$-cation radical state, called compound I. In the presence of chloride anion $\left(\mathrm{Cl}^{-}\right)$, this compound takes place in the chlorination cycle, yielding hypochlorous acid ( $\mathrm{HOCl})$, a strong oxidant [10]. For the peroxidase cycle, compound I is reduced to a second non-radical oxoferryl intermediate, compound II. The final step of the cycle is the reduction of compound II to the native state (Fig. 1). The peroxidase cycle of MPO catalyzes the oxidation of various substrates like nitrite, tyrosine, ascorbate, ... The radicals formed can then oxidize biological molecules such as phospholipids forming the plasma membrane of host

\footnotetext{
* Corresponding author.

E-mail address: pnyssen@uliege.be (P. Nyssen).
} 


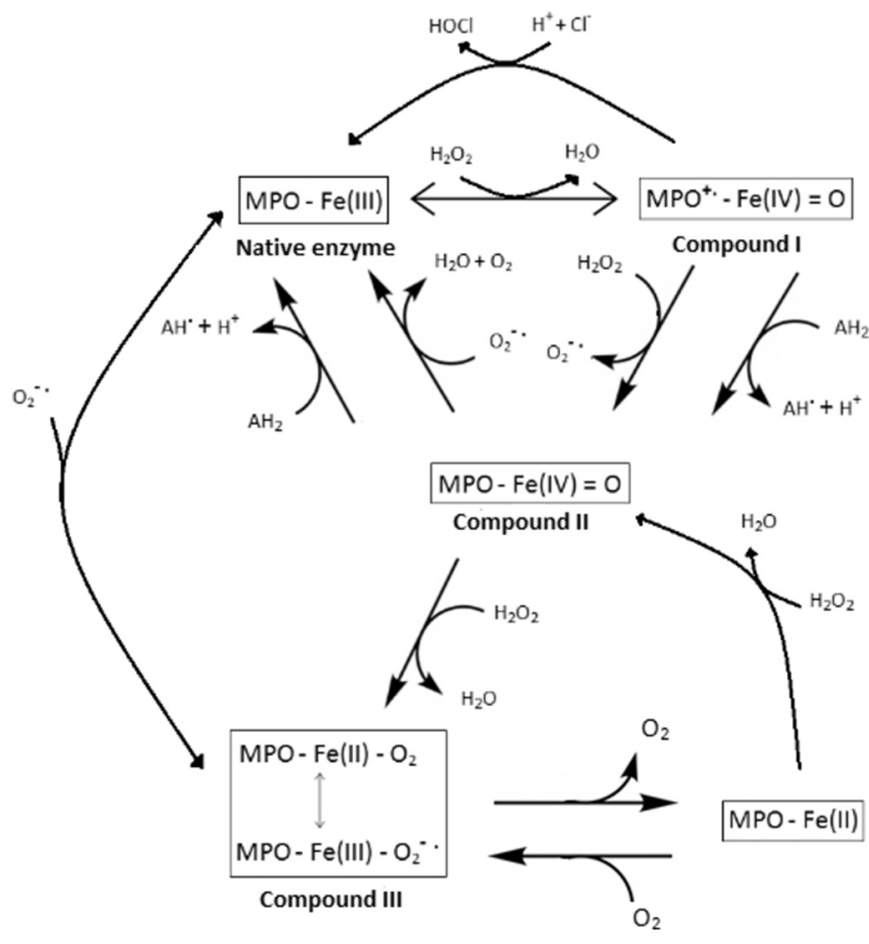

Fig. 1. Peroxidase and chlorination cycles of MPO.

cells and pathogen agents [8,11-14].

Although this oxidative pathway is highly effective in clearing damaged host cells and invading pathogens, the oxidant species lack selectivity and may paradoxically induce oxidative injuries to healthy tissues. Our previous works demonstrated that MPO played a pathophysiological role in various inflammatory diseases in animal $[15,16]$. In human, MPO is involved in tissue damages associated with ischaemia-reperfusion and systemic inflammatory response during sepsis, trauma and shock. [17] Therefore, pharmacological inhibition of MPO may represent an attractive therapeutic opportunity in various inflammatory diseases associated with excessive or protracted activation of PMNs [18].

While researches focused on the design of new molecules [18-23], presenting the best structure to be effective and specific MPO inhibitors, an alternative approach has consisted in examining the anti-MPO activity of a clinically-approved molecule, morphine, at the light of most recent physico-chemical investigation means in order to outline its immunomodulatory and antioxidant potential.

Morphine is an opioid phenanthrene alkaloid and ranges among the most commonly used analgesics to treat moderate to severe pain in clinical practice. The phenolic hydroxyl group of morphine is pivotal for its binding to opioid receptors and analgesic properties (Fig. 2).

This specific group also confers to morphine a phenol-like behavior during its metabolism oxidation by cytochrome P450, especially in liver microsomes [24-27]. The degradation in its derivatives, normorphine, hydroxymorphine, codeine, via the interaction with P450 active site, may suggest the ability of morphine to present an antioxidant behavior towards the peroxidase activity. Morphine has shown to manifest an antioxidant action, such as ROS scavenging effects, free radicals reduction or metal chelation [28]. This antioxidant activity has also been proven in vitro $[29,30]$. In addition, it has also been demonstrated that morphine inhibits the ROS production by inflammatory cells such as PMNs [31]. Moreover, preliminary results have recently shown the ability of morphine to inhibit MPO degranulation from stimulated human PMNs and to interfere with both peroxidase and chlorination activities of the MPO enzyme as reported Minguet et al., in a personal communication [32].

Considering the important involvement of MPO in the inflammatory response, we sought to further evaluate the inhibitory activity of morphine on MPO and outline the mechanisms of morphine-MPO interactions. The aim of this study was to determine if morphine can belong to reversible inhibitors of the enzyme in order to precise its antioxidant and anti-inflammatory potential. The antioxidant action of morphine has been compared to the one of antioxidant reference molecules, having already demonstrated their ability to interact with MPO (quercetin, gallic acid and ascorbic acid (Fig. 2)) [14,33-37]. First, the potential anti-catalytic property of morphine was tested on MPO with SIEFED, Specific Immunological Extraction Followed by Enzyme Detection, an immunological technique able to measure specifically the MPO activity after exposure to potential inhibitors [37,38]. The molecular docking between morphine and MPO in comparison with the selected reference molecules was performed to complete the anti-catalytic experiments and obtain key information about the kind of interaction between the tested ligands and the enzyme [18,20,39,40]. The influence of morphine on MPO peroxidase cycle intermediates was investigated thanks to the UV-visible absorption. UV-visible spectroscopy is an effective technique to study the direct action of a substrate on a peroxidase enzyme [21,41-44]. Likewise, the ABTS model $[45,46]$ was performed to study the reducing action of morphine on the MPO peroxidase cycle. As the peroxidase activity undergoes radical processes, it was interesting to monitor the reducing action of morphine using electron paramagnetic resonance technique (EPR) in the presence of ABTS as co-substrate.

\section{Materials and methods}

\subsection{Materials}

Morphine (under chlorhydrate form) was purchased from Sterop group (Brussels, Belgium). From the stock solution $(10 \mathrm{mg} / \mathrm{ml})$, the diluted solutions were freshly prepared in distilled water to obtain a final concentration range from $10^{-6} \mathrm{M}$ to $510^{-4} \mathrm{M}$. The use of concentrations, higher than clinic ones, from $10^{-6} \mathrm{M}$ and below $[47,48]$, allows to further investigated the mechanism of interaction between morphine and MPO. The stock solution of MPO (Merck Millipore, Leuven, Belgium) was prepared in phosphate buffer $(50 \mathrm{mM}) \mathrm{pH} 7.4$. Hydrogen peroxide was purchased from Merck Millipore and ABTS (2,2'-azino-bis(3-ethylbenzothiazoline-6-sulphonic) acid) was purchased from Amresco (Solon, USA). Different reference inhibitors were used in this study: quercetin (Fluka AG Chemische Fabrik, Saint-Louis,<smiles>O=C(O)c1cc(O)c(O)c(O)c1</smiles>

Gallic acid<smiles>O=C1O[C@H]([C@@H](O)CO)C(O)=C1O</smiles>

Ascorbic acid<smiles>O=c1c(O)c(-c2ccc(O)c(O)c2)oc2cc(O)cc(O)c12</smiles>

Quercetin

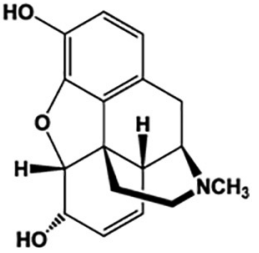

Morphine

Fig. 2. Chemical structures of the antioxidant molecules studied. 


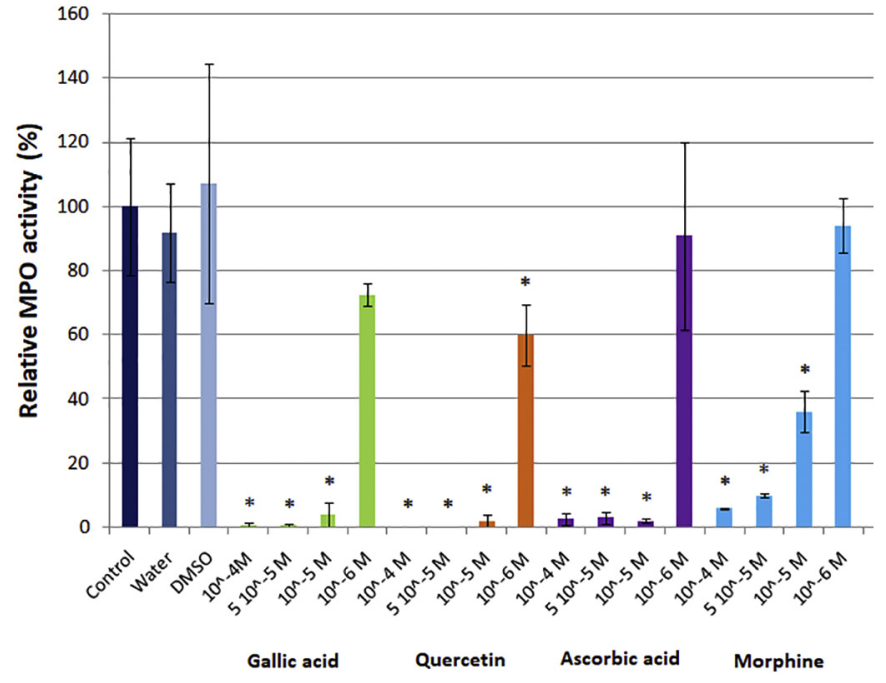

Fig. 3. Effect of gallic acid, quercetin, ascorbic acid and morphine on MPO activity. The percentages of inhibition of MPO activity for each molecule were calculated versus their respective solvent control. ${ }^{*} P<0.05$ versus respective control was found statistically significant, otherwise NS: not significant. Data are given as mean $\pm \operatorname{SD}(n \leq 6)$.

USA), gallic acid and ascorbic acid (UCB, Brussels, Belgium). Gallic acid and ascorbic acid were diluted in distilled water, whereas quercetin was diluted in DMSO. For the SIEFED experiment, sodium nitrite was from Sigma Aldrich (St-Louis, USA) and Amplex red from Molecular Probes (Invitrogen, Merelbeke, Belgium).

\subsection{EPR studies and UV-visible absorption}

All the EPR spectra were recorded on a Bruker ER082C spectrometer (EMX-micro, Karlsruhe, Germany) at room temperature with a $100 \mathrm{kHz}$ modulation frequency $(9.78 \mathrm{GHz}$ microwave frequency, $18 \mathrm{~mW}$ microwave power). The micro-capillaries containing the samples were placed in an EPR quartz cell, to be inserted in the cavity. Absorption spectra were recorded with a multichannel (1024-element diode array) Agilent 8453 spectrophotometer (Hewlett-Packard, Waldbronn, Germany) and the samples were placed in a quartz cell, with an optical path $1 \mathrm{~cm}$. The concentration of MPO has been determined by measuring the absorbance of the native enzyme Soret band at $430 \mathrm{~nm}$ $\left(\varepsilon_{430 \mathrm{~nm}}=91,000 \mathrm{M}^{-1} \mathrm{~cm}^{-1}[14]\right)$.

\subsection{SIEFED assay}

Solutions containing $50 \mathrm{ng} / \mathrm{ml}$ of MPO and selected inhibitors at several concentrations were incubated for $10 \mathrm{~min}$ at $37^{\circ} \mathrm{C}$, in PBS buffer. One hundred microliters of each solution were placed in a 96wells microtiter plate (Combiplate $8 \mathrm{~EB}$ ), from Thermo Scientific (Breda, Netherlands), coated with rabbit anti-human MPO polyclonal antibodies (CORD, Belgium). Solvent controls were performed by replacing the inhibitors by their solvent (water or DMSO). The plate was incubated for $2 \mathrm{~h}$ at $37^{\circ} \mathrm{C}$. The washing step consisted of four washes of the wells with a PBS solution containing $0.1 \%$ Tween 20 . The peroxidase cycle of MPO was initiated by adding in each well: $10 \mu \mathrm{l}$ of sodium nitrite $(50 \mathrm{mM})$ and $100 \mu \mathrm{l}$ of a solution containing $40 \mu \mathrm{M}$ Amplex red and $10 \mu \mathrm{M}$ of $\mathrm{H}_{2} \mathrm{O}_{2}$ in phosphate buffer $(50 \mathrm{mM})$ at $\mathrm{pH}=7.5$.

The solutions, not used for the coated plate, were used to make an ELISA direct analysis. One hundred microliters of the solution were added in the 96-wells plate, free of anti-human MPO antibodies. The peroxidase cycle of MPO was initiated in the same way than for SIEFED experiment without incubation and washing steps.

A spectrometer Fluoroskan Ascent (Thermo Scientific, Waltham, USA) was used to measure the fluorescence signal of oxidized Amplex red at $590 \mathrm{~nm}$ (excitation wavelength $544 \mathrm{~nm}$ ), for $30 \mathrm{~min}$.

The statistical test used on the results is ANOVA: one way ANOVA with Dunnett post test. The results for the tested compounds were all compared to their respective control (distilled water or DMSO). A $P$ value of $<0.05$ was considered significant.

\subsection{Docking}

Molecular docking of the MPO-inhibitors complexes was performed with the program Gold [49]. The force-fields scoring function used was Goldscore. In the procedure, the enzyme structure was extracted from the PDB crystal structure 4C1M and energy minimized with the program Yasara [50], after the suppression of the co-crystallized inhibitor HX1. The oxidation state of the two heme iron ions has been modified to obtain the $\mathrm{Fe}^{3+}$ state. A $15 \AA$ cubic zone centered on the iron has been defined to limit the positioning of the inhibitor. The selected docking parameters allowed to reproduce the crystallographic structure of the MPO-HX1 complex. The visualization of the docking solutions was done with Pymol [51] and the determination of the binding between the inhibitors and MPO has been realized with LigPlot [52]. Yasara was used to minimize the complexes structures, to perform a molecular dynamics simulation and to evaluate the complexes bindingenergy.

\section{Results and discussion}

\subsection{SIEFED experiment}

The SIEFED and the direct analysis (see Materials and methods) allow to investigate the interaction between MPO and a potential inhibitor. Whereas, the SIEFED indicates the ability of a ligand to bind to the enzyme active site and the reversibility of this interaction, the direct analysis informs about a global enzyme-ligand interaction, without being able to distinguish between the stoichiometric reducing action on the MPO peroxidase cycle and the anti-catalytic one. These two techniques are therefore complementary. Indeed, the absence of MPO activity inhibition measured by SIEFED does not mean the absence of interactions between the ligand and the enzyme.

The results of the direct analysis are summarized in Fig. 3. This experiment allows to study simultaneously two inhibitors action pathways on MPO: the anti-catalytic and the stoichiometric reducing actions on the peroxidase cycle. Indeed, without the washing step, the tested molecules could compete or interfere with the revelation substrates (Amplex Red, nitrite) used to measure MPO activity.

Quercetin and gallic acid presented a total inhibition on the MPO activity, at concentrations ranging from $10^{-5} \mathrm{M}$ to $10^{-4} \mathrm{M}$. Their inhibition action at the lowest concentration of $10^{-6} \mathrm{M}$, decreased to around $40 \%$. These results demonstrate the strong interaction between these two polyphenols and MPO. In contrast, morphine exhibited a concentration dependent inhibitory action, with $>60 \%$ inhibition already at the concentration $10^{-5} \mathrm{M}$. The use of high concentrations, but not relevant in a clinical use, allowed to investigate the interaction mechanism between morphine and MPO. Indeed, the direct assay proves the capacity of morphine to compete with substrates to get close to and interact with the active site. According to the dose-dependent behavior observed, a clinic relevant concentration of $3.510^{-6} \mathrm{M}(1 \mu \mathrm{g} /$ $\mathrm{ml}$ ) should present an MPO activity inhibitory action. Ascorbic acid inhibited $97 \%$ of the MPO activity at concentrations ranging from $10^{-5} \mathrm{M}$ to $10^{-4} \mathrm{M}$, but presented a weaker inhibitory action (9\%) than quercetin and gallic acid at $10^{-6} \mathrm{M}$.

The introduction of a washing step in the SIEFED protocol allows to study the potential binding of the ligand to the MPO structure and therefore to evaluate the reversibility of the inhibitor interaction. The SIEFED assay performed in the presence of solvent controls (DMSO and $\mathrm{H}_{2} \mathrm{O}$ ) showed only a $10 \%$ decrease of the MPO activity for DMSO and no significant effect for water versus the enzyme control (without 


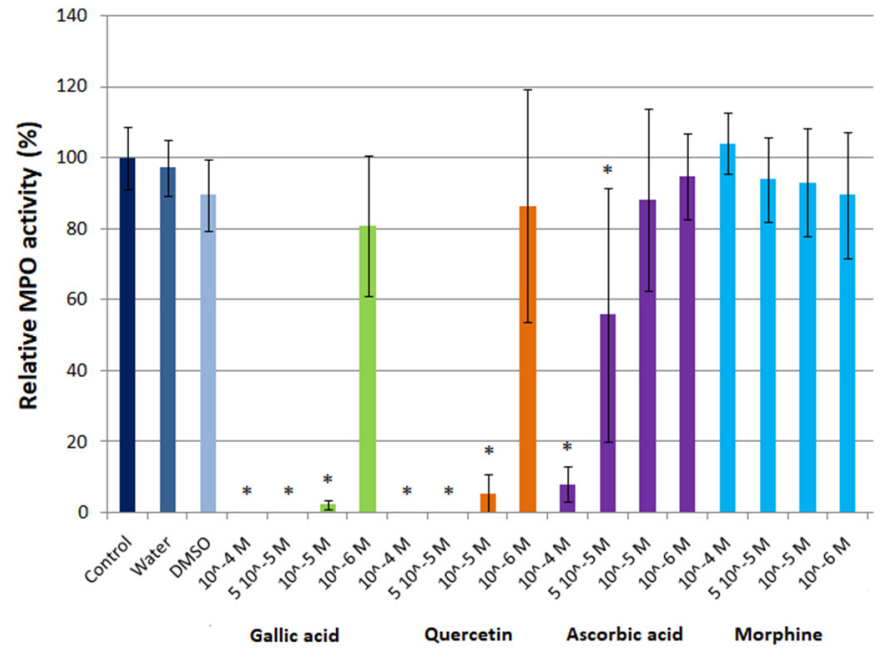

Fig. 4. Effect of gallic acid, quercetin, ascorbic acid and morphine on MPO activity measured by the SIEFED method. The percentages of inhibition of MPO activity for each molecules were calculated versus their respective solvent control. ${ }^{*} P<0.05$ versus respective control was found statistically significant, otherwise NS: not significant. Data are given as mean $\pm \operatorname{SD}(n \leq 6)$.

solvent or tested molecules) (Fig. 4). In contrast, the two polyphenols, gallic acid and quercetin, exhibited a total inhibition of the MPO activity at concentrations equal or higher to $10^{-5} \mathrm{M}$. However, when used at intermediate concentrations $\left(2.510^{-5} \mathrm{M}, 510^{-5} \mathrm{M}\right.$ and 7.5 $10^{-5} \mathrm{M}$ ), both polyphenols do not either showed any dose-dependent action (Data not shown). In contrast, the assay done in the presence of morphine, at concentrations ranging from $10^{-6} \mathrm{M}$ to $10^{-4} \mathrm{M}$, did not induce any inhibition on the MPO activity. While ascorbic acid exhibited a concentration dependent inhibitory action and reached quite a complete inhibition (92\%) at $10^{-4} \mathrm{M}$ (Fig. 4).

Our SIEFED results clearly suggest the lack of an anti-catalytic action of morphine, or at least, the weakness of the bonds, potentially formed between morphine and MPO during incubation and broken during the washing step. The results shown on Fig. 4 indicate the total elimination of morphine in solution during the washing step, in our experimental conditions, illustrating the reversibility of its inhibitory action towards MPO. In comparison to morphine, it appears that polyphenols, like quercetin and gallic acid, form stronger bonds with MPO and its active site.

Furthermore, when comparing the 3D structure and the steric hindrance of morphine to that of small size molecules like gallic acid or molecules with planar structure like quercetin, we can state that the insertion of morphine in the enzyme catalytic pocket is difficult likewise the formation of bonds with important amino acids. The weak insertion probability may explain the lack of MPO activity inhibition by morphine, at all the concentrations tested.

Gallic acid and quercetin presented a strong anti-catalytic action, event at lower concentration of $10^{-6} \mathrm{M}$. These results are in agreement with previous SIEFED and docking studies. [37,53] The authors show that the small size of gallic acid, the planarity and the flexibility of quercetin, and the presence of hydroxyl groups, especially the presence of a pyrogallol group in gallic acid, support the simple entry of these molecules inside the MPO active site and their strong fixation, resisting to the washing step. However, the stronger inhibitory action observed at the concentration of $10^{-6} \mathrm{M}$ with the direct analysis, around $40 \%$ in comparison to almost $20 \%$ for the SIEFED, suggest that the inhibitory action of these molecules can be explain mainly by their binding to the active site and secondly by a competition as reducing substrates with the revelation substrates.

In the case of ascorbic acid, a dose-dependent action on the MPO activity was observed, with an inhibitory activity of $92 \%$ at $10^{-4} \mathrm{M}$.

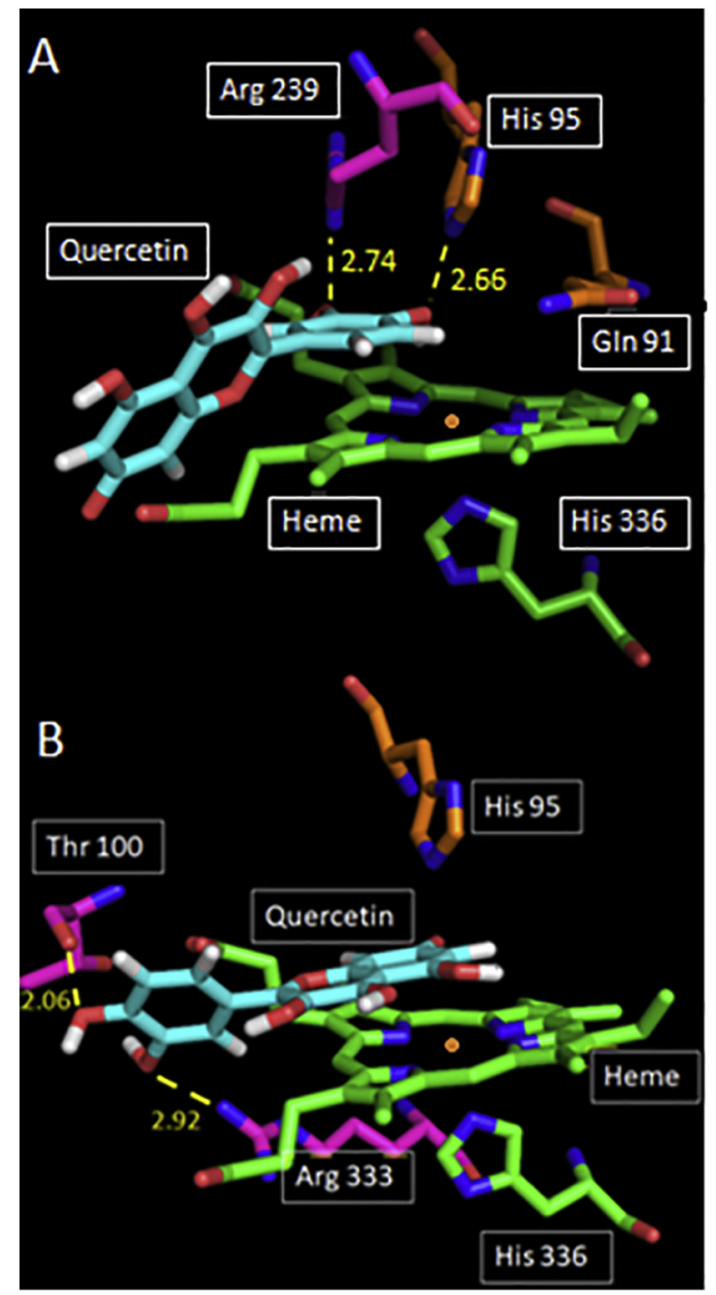

Fig. 5. The two most plausible docking solutions of the quercetin-MPO complex by GOLD. The yellow dashed lines represent the hydrogen bond between the ligand and MPO residue. Selected distances (in Angström) are given on the scheme.

Nevertheless, the anti-catalytic action is less important than those of polyphenols. As for morphine, the main MPO inhibition pathway of ascorbic acid is a reducing action on the peroxidase cycle. This activity goes together with the low anti-catalytic activity, to almost totally inhibit the MPO activity, at concentrations superior to $10^{-6} \mathrm{M}$, in the direct analysis.

\subsection{Docking}

Docking simulations have been realized to determine the capacity of the four molecules analyzed by SIEFED (morphine, quercetin, gallic acid, ascorbic acid), to enter the active site of MPO, and to investigate their binding mode with amino acids near the heme cavity. The different inhibitors were docked in the heme pocket using the GOLD program. Five runs have been performed for each inhibitor, with the aim to determine the most frequent solutions and ensure their reproducibility.

The docking of quercetin into the MPO active site gave two plausible solutions (Fig. 5). The first one is similar to that reported by Shiba et al. [53], obtained with FlexX, where the B-ring is stacked parallel to the heme, near the $\mathrm{D}$ pyrrole ring.

Quercetin forms hydrogen bonds with two amino acids. Among them, His 95 is essential to trigger the MPO peroxidase cycle, by linking with $\mathrm{H}_{2} \mathrm{O}_{2}$. The bond between quercetin and this amino acid residue 
(Fig. 5A) explains the anti-catalytic action of the inhibitor as observed by SIEFED.

The second solution (Fig. 5B) places the linked aromatic cycles of the molecule above and parallel to the heme plane. The B-ring is oriented between the two propanoic acid side chains of the porphyrin. This solution is the most frequent one obtained with Gold in our modeling conditions. The difference between our results and those reported by Shiba et al. [53] can be explained by the use of different scoring function and a different input enzyme structure.

The comparison of our two docking solutions with the SIEFED results, is in favor of the solution A. Indeed, in solution B, quercetin binds with two flexible cavity residues, in particular Thr 100. Being positioned at the entrance of the heme cavity, its mobility induces a weaker bond with the inhibitor. Indeed, the comparison of the two solutions A and B binding energy (data not shown), confirms the higher stability of the complex A.

As for quercetin, the small number of different complex solutions between gallic acid and MPO, provided by GOLD, informs about the good stability of the complex. Indeed, it shows the ease of the docking algorithm to position the ligand to maximize the interactions with amino acids near the heme. The limited number of solutions indicates the good reliability of the docking results. In the case of gallic acid, a solution stands out (Fig. 6), where the carboxyl group is above the heme center and is linked to both His 95 and Gln 91 residues via a hydrogen bond. The ring is above the $\mathrm{D}$ pyrrole ring and slightly leaning compared to the heme plane, placing a hydroxyl group between the two propanoic acid side chains of the heme. The association of the bond with the iron ion and His 95 is in agreement with the high anti-catalytic activity of gallic acid.

The docking approach gave a restricted number of solutions for the complex between morphine and MPO. The most frequent solution places morphine in front of the heme (Fig. 7). In this position, morphine is far from the heme and specific amino acids like His 95 contrary to quercetin or gallic acid. The morphine 3D structure makes its orientation difficult in relation to the heme plane. No morphine cycle is parallel to the heme plane and the structure is tilted in a way to place the hydroxyl function of the phenol ring between the two heme propanoic acid side chains. The binding of morphine with two flexible residues

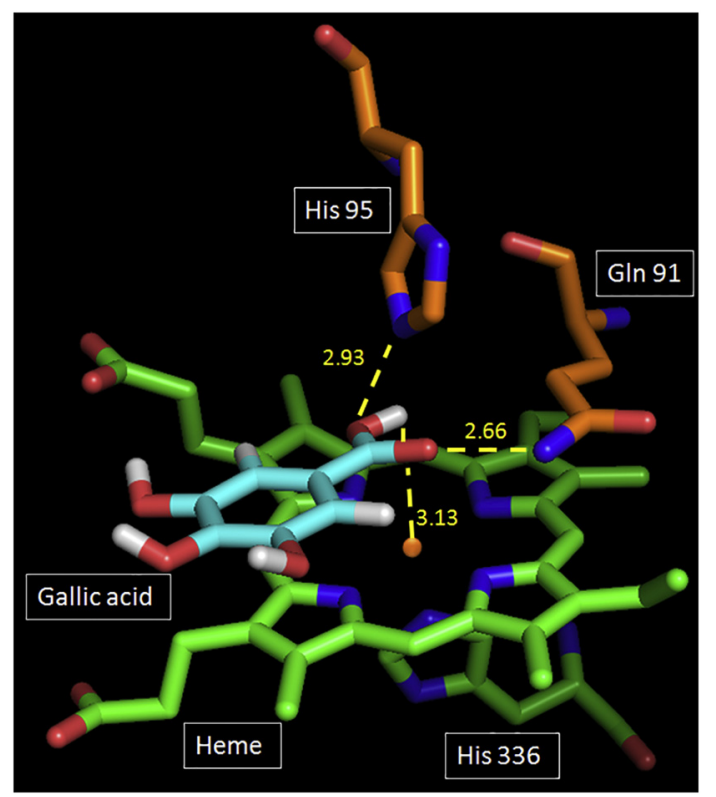

Fig. 6. The most plausible docking solution of the gallic acid-MPO complex by GOLD. The yellow dashed lines represent the hydrogen bond between the ligand and MPO residue. Selected distances (in Angström) are given on the scheme.

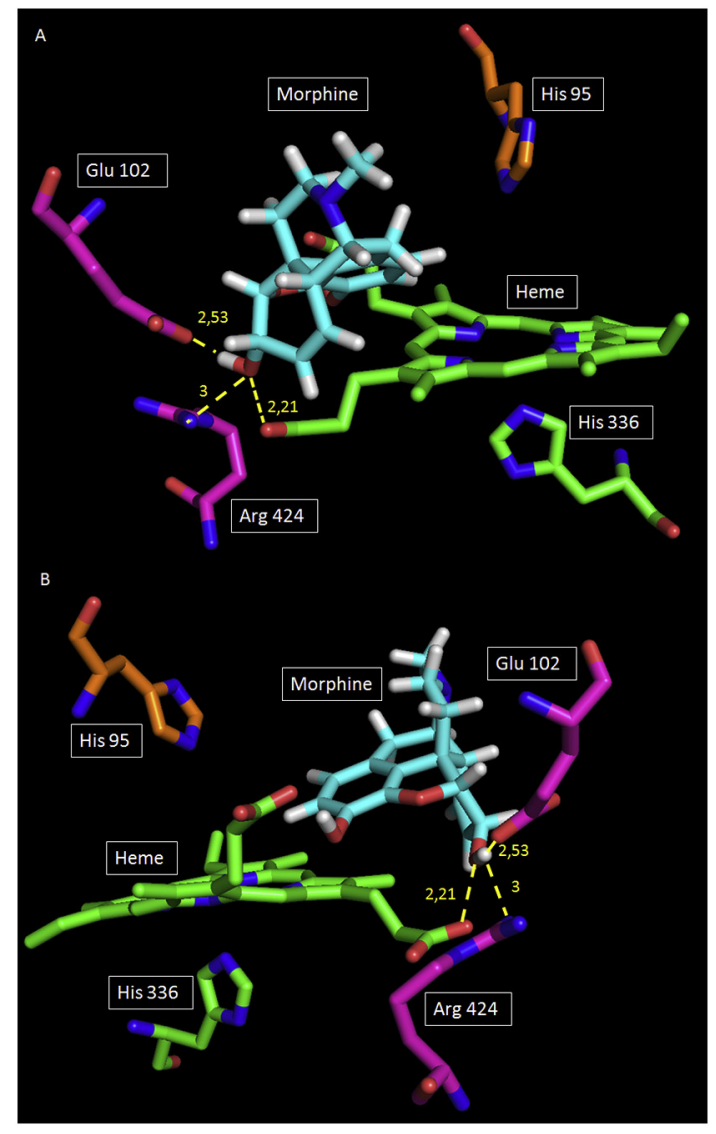

Fig. 7. The most plausible docking solution of the morphine-MPO complex by GOLD. The yellow dashed lines represent the hydrogen bond between the ligand and MPO residue. Selected distances (in Angström) are given on the scheme. A and B represent the same solution in two different points of view.

(Fig. 7) placed away from the heme and to one of the flexible heme chain explains the low binding of the molecule with the enzyme, which does not resist to the SIEFED washing step. Indeed, the evaluation of the morphine-MPO complex binding energy shows the very low binding ability of morphine in comparison to quercetin and gallic acid.

In contrast to the other tested ligands, the GOLD program gave a large number of possible solutions for the structure of the ascorbic acidMPO complex. This illustrates the difficulty to define a unique satisfying solution and therefore the complexity to place the ascorbic acid molecule in an energy optimum way inside the MPO cavity. Fig. 8 shows the most plausible solution obtained with our parameters. The positioning of the alkyl chain to the five atoms cycle does not allow the molecule to be sufficiently close to the heme to form a bond with His 95 and to place the cycle parallel to the heme plane. The molecule is inserted between the two heme propanoic acid side chains which allows one of them to establish hydrogen bond with one alcohol function of the alkyl chain. Two other bonds can be observed with two arginine residues. The absence of binding with amino acids, positioned deeper inside the cavity, is in agreement with the SIEFED results, showing a weak inhibitory effect on the MPO activity.

\subsection{Optical measurements- direct action of morphine on the peroxidase cycle of MPO}

Based on a dose-dependent action demonstrated by the ELISA direct assay, accompanied by the lack of MPO activity inhibition during SIEFED, we were particularly interested to understand better the mechanism of action of morphine towards the peroxidase activity of MPO. Therefore, we designed a set of experiments using spectroscopic 

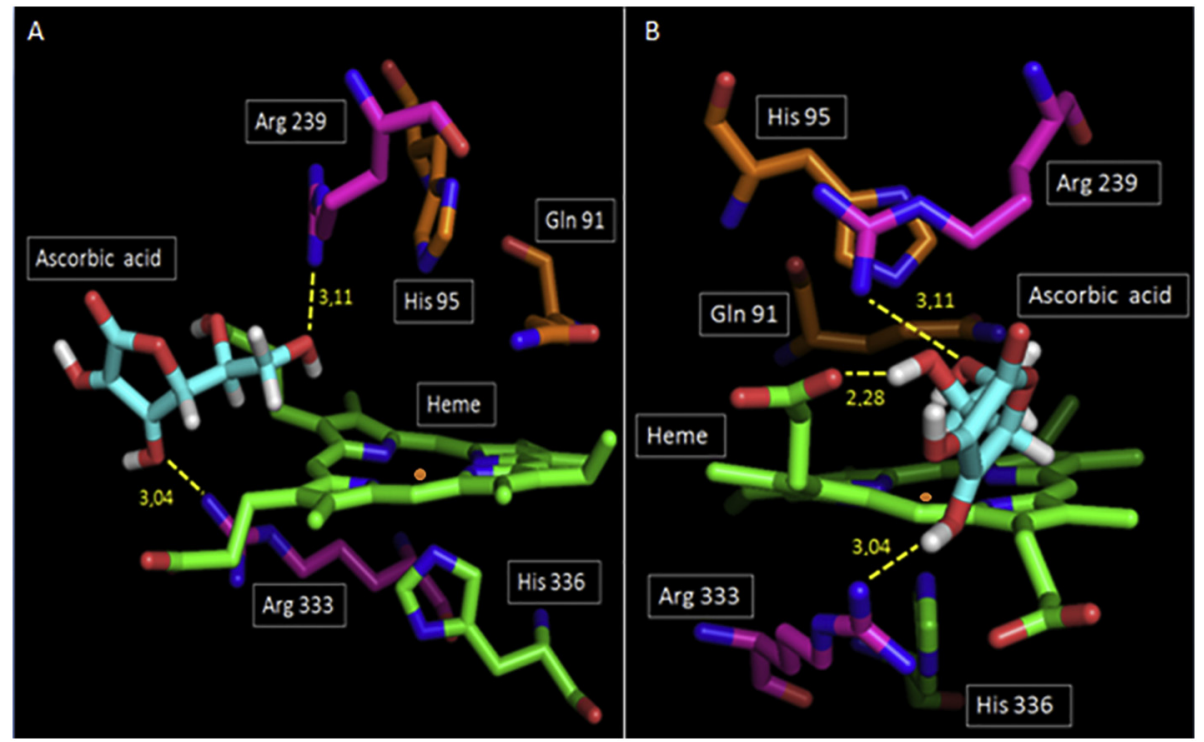

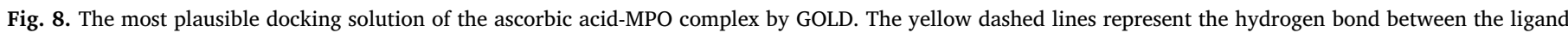
and MPO residue. Selected distances(in Angström) are given on the scheme. A and B represent the same solution in two different points of view.

approach (optical absorption and EPR spectroscopy). For both methods, we did not investigate the stoichiometric activity of quercetin and gallic acid. Fig. 9 illustrates the action of morphine, as substrate, on the peroxidase cycle of MPO triggered by the addition of an excess of $\mathrm{H}_{2} \mathrm{O}_{2}$. The action of ascorbic acid has been compared to the one morphine, regarding their similar interaction mode with MPO as highlighted by the SIEFED and the direct analyses.

The spectrum obtained immediately after the addition of $\mathrm{H}_{2} \mathrm{O}_{2}$ is attributed to compound II, characterized by a bathochromic shift of the Soret band, centered at $455 \mathrm{~nm}$ (Fig. 9). The compound I, being extremely reactive, is rapidly reduced by its interaction with hydrogen peroxide and is not observed in our conditions. In the absence of a reducing substrate in solution (Fig. 9A), compound II returns to the native state by interacting with the superoxide ions generated by the reduction of compound I. The cycle of MPO continues until the total consumption of $\mathrm{H}_{2} \mathrm{O}_{2}$. $[14,54,55]$ After $3 \mathrm{~min} 30 \mathrm{~s}$, the pursuit of the absorbance decrease at $455 \mathrm{~nm}$ and the increase at $430 \mathrm{~nm}$ illustrate the conversion of compound II into the native enzyme by the interaction with superoxide ions remaining in solution after the consumption of the entire $\mathrm{H}_{2} \mathrm{O}_{2}$. This transformation, extremely slow in the absence of a reducing substrate, is characterized by the appearance of an isosbestic point at $442 \mathrm{~nm}$.

Paumann-Page et al. [14] showed that, in the presence of a 40-fold excess of $\mathrm{H}_{2} \mathrm{O}_{2}$, no more changes in the absorption spectrum were observed after $120 \mathrm{~min}$, indicating the end of the enzyme cycle. They have also demonstrated that the presence of a reducing substrate like ascorbic acid, accelerates the cycle, particularly the return of compound II to the native state and thus protects the enzyme against the destructive action of an excess of hydrogen peroxide [55]. Indeed, $\mathrm{H}_{2} \mathrm{O}_{2}$ plays the role of suicide inhibitor by allowing the formation of compound III. This compound can then react again with $\mathrm{H}_{2} \mathrm{O}_{2}$ to form ROS inside the enzyme active site, causing oxidative damages on the heme and amino acids. The destroyed enzymes do not contribute to the absorption signal anymore, which explains the loss of the native enzyme Soret peak absorbance at the end of the enzyme cycle [14].

The results showed in Fig. 9 B, C and D are in accordance with those reported by Paumann-Page et al. [14]. Even if the measures, realized over a period of $10 \mathrm{~min}$, did not allow to reach the equilibrium state of MPO in solution, they enable to demonstrate the comparable action of morphine and ascorbic acid, as reducing substrate in the peroxidase cycle of MPO.
The measure of the absorbance at $455 \mathrm{~nm}$ directly after the triggering of the MPO cycle, in the absence and presence of reducing molecules, shows that the substrates accelerate the transition of compound I into compound II. Morphine can get close to the active site of MPO and interact without inactivating the enzyme. The phenol group of the molecule is suspected to be responsible for its reducing action, by giving up an electron to the $\pi$-radical state of the enzyme [24]. The use of two morphine concentrations suggests the dose-dependent action of this molecule. The first one, $3.510^{-6} \mathrm{M}(1 \mu \mathrm{g} / \mathrm{ml})$, allows to demonstrate the interaction between a clinical concentration of morphine and the enzyme. To further investigate morphine action mechanism, a 5 $10^{-5} \mathrm{M}$ concentration has been used.

The return of compound II to the native state, after the total consumption of $\mathrm{H}_{2} \mathrm{O}_{2}$, is characterized by the isosbestic point at $442 \mathrm{~nm}$. Its appearance shows that compound II does not pass through another intermediate while going back to the native enzyme. Compound III is not formed anymore. The time interval to achieve the apparition of this point informs on the cycle run's rate and is of $3 \mathrm{~min} 30 \mathrm{~s}$ in the absence of reducing substrate. The addition of $510^{-5} \mathrm{M}$ of morphine or ascorbic acid accelerates the total hydrogen peroxide consumption to about $2 \mathrm{~min}$.

The two studied molecules protect MPO against the destructive effect of an excess of $\mathrm{H}_{2} \mathrm{O}_{2}$. The increase of the absorbance at $430 \mathrm{~nm}$, $10 \mathrm{~min}$ after the triggering of the cycle, is about $40 \%$ in the presence of $510^{-5} \mathrm{M}$ morphine and about $30 \%$ in the presence of similar concentration of ascorbic acid versus control without addition of any substrate. The increase obtained with the clinical concentration of morphine is lower than $10 \%$. By accelerating the peroxidase cycle of MPO, morphine and ascorbic acid reduce the ferrous state [14]. In clinical conditions, the iron released in the extra-cellular medium might be harmful by producing extremely reactive hydroxyl radicals via a Fenton-like reaction. Therefore, by protecting MPO, morphine could have a protective action on the organism.

3.4. EPR measurements - study of the action against the oxidation of ABTS by the peroxidase cycle of MPO

The efficiency of both morphine and ascorbic acid as substrate, has been further investigated with EPR. Indeed, the MPO peroxidase cycle involves radical processes, which can efficiently be studied in EPR spectroscopy. In the present experiment, the two molecules have been 

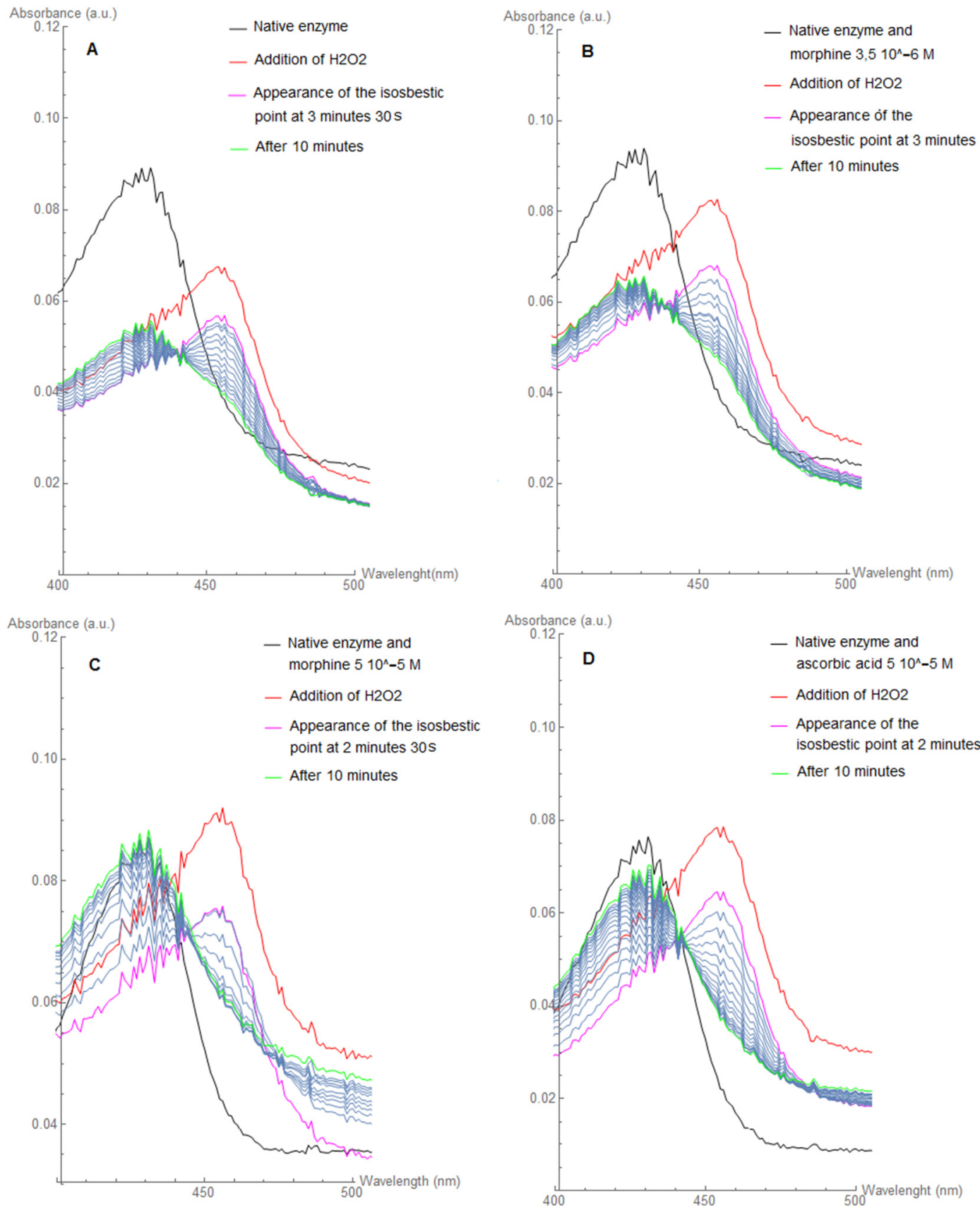

Fig. 9. Effect of morphine and ascorbic acid on the transition of compound I of MPO to compound II. A: the peroxidase cycle is initiated by adding $\mathrm{H}_{2} \mathrm{O}_{2}\left(3.410^{-4} \mathrm{M}\right)$ to a solution containing $9.510^{-7} \mathrm{M}$ MPO. B: the peroxidase cycle is initiated by adding $\mathrm{H}_{2} \mathrm{O}_{2}\left(3.410^{-4} \mathrm{M}\right)$ to a solution containing $9.510^{-7} \mathrm{M}$ MPO and $3.510^{-6} \mathrm{M}$ morphine. $\mathrm{C}$ : the peroxidase cycle is initiated by adding $\mathrm{H}_{2} \mathrm{O}_{2}\left(3.410^{-4} \mathrm{M}\right)$ to a solution containing $9.510^{-7} \mathrm{M}$ MPO and $5.510^{-5} \mathrm{M}$ morphine. D: the peroxidase cycle is initiated by adding $\mathrm{H}_{2} \mathrm{O}_{2}\left(3.410^{-4} \mathrm{M}\right)$ to a solution containing $9.510^{-7} \mathrm{M} \mathrm{MPO}$ and $5.510^{-5} \mathrm{M}$ ascorbic acid.

studied regarding their protective action on ABTS, a substrate frequently used in enzymatic studies, against its oxidation by the peroxidase cycle of MPO. Morphine and ascorbic acid, first added in solution with ABTS before the triggering of the cycle, can compete with the ABTS molecules to interact with compounds I and II of the enzymes. Three concentrations $\left(510^{-5} \mathrm{M}, 10^{-4}\right.$ Mand $510^{-4} \mathrm{M}$ ), higher than the clinical concentration range, allow to further investigate the mechanism of action of both molecules.

Morphine presents a dose-dependent reducing action on the peroxidase cycle of MPO, with an inhibition of the ABTS ${ }^{+}$formation from about $20 \%$ at $510^{-5} \mathrm{M}$ to $85 \%$ at $510^{-4} \mathrm{M}$ (Fig. 10). In accordance with the SIEFED results, ascorbic acid is a more efficient substrate than morphine with at least $80 \%$ of inhibition at the three concentrations.
The hydroxyl groups are proven, for ascorbic acid, to be at the origin of its antioxidant activity. The association of the reducing and the low anti-catalytic actions can explain the stronger inhibition of the $\mathrm{ABTS}^{+}$production by ascorbic acid. Indeed, ascorbic acid, is able to get close not only to the iron atom but also to the most important active site amino acids, which are essential to trigger the peroxidase cycle by the natural substrate $\mathrm{H}_{2} \mathrm{O}_{2}$. At this position, ascorbic acid is able to transfer an electron to oxidant compound I or II. Moreover, at high concentrations, from $510^{-5} \mathrm{M}$, ascorbic acid presents an un-negligible anti-catalytic action (Fig. 3). The stoichiometric inhibition of the ABTS oxidation, clearly demonstrated the ability of morphine to interact with MPO and therefore, to compete with ABTS when reacting as reducing substrate. The study of Borges et al. [24] on the redox properties of 


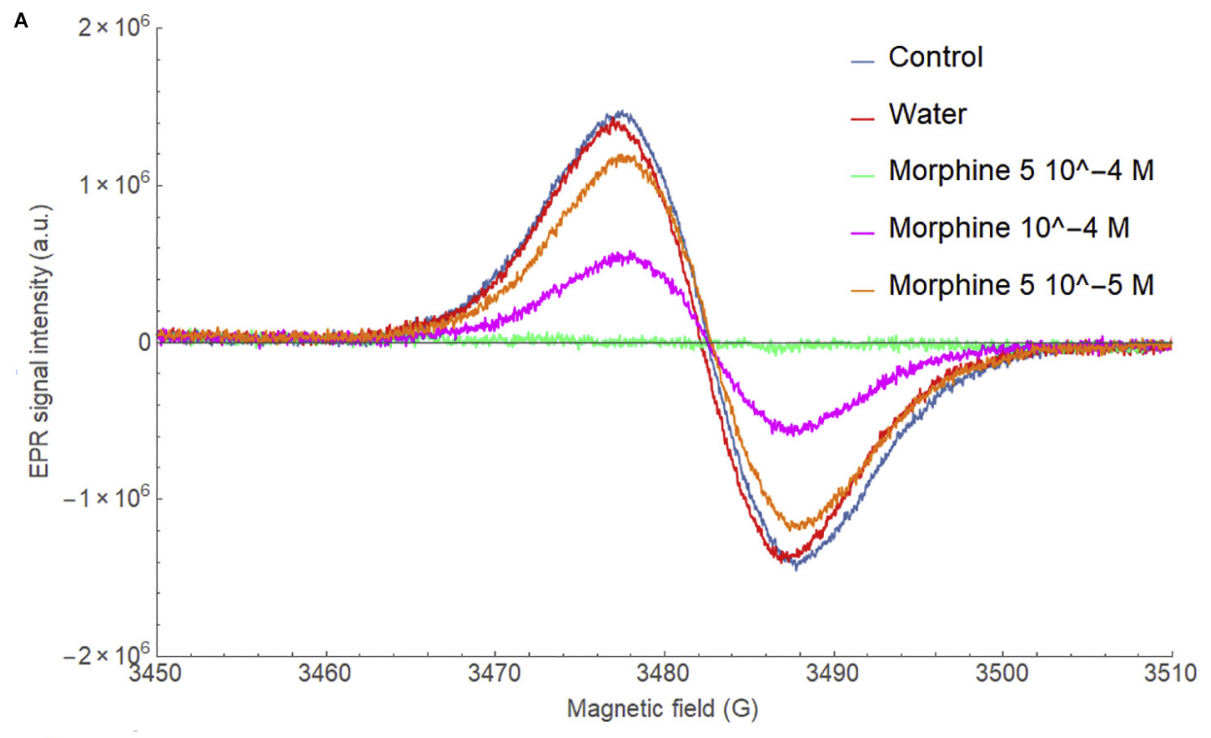

B

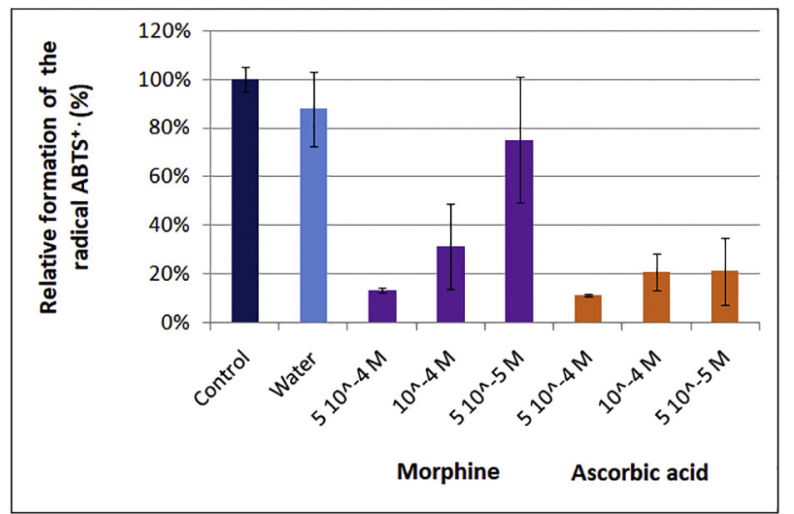

Fig. 10. Illustration by EPR of the inhibition action of morphine, on the formation of the cation radical ABTS ${ }^{+}$by the enzymatic system $\mathrm{MPO}-\mathrm{H}_{2} \mathrm{O}_{2}:[\mathrm{MPO}]=1.07$ $10^{-7} \mathrm{M},\left[\mathrm{H}_{2} \mathrm{O}_{2}\right]=2.410^{-4} \mathrm{M}$, [ABTS $]=3.7410^{-4} \mathrm{M}$ and $\left[\mathrm{NaNO}_{2}\right]=510^{-3} \mathrm{M}$. B: Comparison of the action of morphine and ascorbic acid. Data are given as mean $\pm \mathrm{SD}(n=3)$ (spectra acquisition parameters: time constant $20 \mathrm{~ms}$, time conversion $40 \mathrm{~ms}$, modulation amplitude $2 \mathrm{G}$, sweep number 6 ).

morphine, indicates that the presence of a phenol group may be at the origin of this antioxidant property, based on its high hydrogen transfer capacity. Furthermore, our results indicate that the higher the concentration in solution, the bigger the steric effects preventing ABTS to be oxidized by the enzyme. This latter observation brings additional explanation to the strong inhibition of the $\mathrm{ABTS}^{+}{ }^{+}$formation seen at the concentration of $510^{-4} \mathrm{M}$.

\section{Conclusion}

Morphine is an opioid analgesic commonly used in clinical practice. Recent investigations have pointed to non-analgesic effects of morphine involving antioxidant action and inhibition of several components of the immune system. MPO, a pivotal enzyme of the oxidative response of polymorphonuclear neutrophils is a potential target of morphine side effects. In this study, we characterized the physicochemical features of morphine-MPO interactions at the light of efficient investigation tools. We demonstrated that morphine has a direct action on MPO, especially on its peroxidase cycle. However, the anti-catalytic effect of morphine is weak and reversible due to its 3D structure leading to steric constraints avoiding efficient entering and binding in the active site of MPO. Nevertheless, since these effects may occur at therapeutic relevant concentrations, we raise the possibility that morphine effects on MPO contribute to immunomodulatory and antioxidant effects of the opioid during clinical use. However, a further study is needed to determine the inhibition constant and characterize the potential competitive inhibition mechanism of morphine on MPO. Likewise, to deepen the study of the activity of morphine in a clinical point of view, the inhibitory action of its hepatic metabolites, morphine-3-glucuronide and morphine-6-glucuronide, has been investigated thanks to docking. Based on these interesting preliminary results, another set of experiments will be performed using the SIEFED and the spectroscopic techniques.

\section{Acknowledgments}

Access to the computating facilities of the PTCI platform of UNamur is deeply acknowledged. This work was supported by grants from the University of Liège (Uliège).

\section{References}

[1] J.A. Smith, Neutrophils, host defence, and inflammation: a double-edge sword, J. Leukoc. Biol. 56 (1994) 672-686.

[2] C.C. King, M.M. Jefferson, E.L. Thomas, Secretion and inactivation of myeloperoxidase by isolated neutrophils, J. Leukoc. Biol. 61 (1997) 293-302.

[3] S. Derochette, phD Thesis, University of Liège, (2014).

[4] L.A. Rice-Evans, A.T. Diplock, M.C.R. Symons, Techniques in Free Radical Research, Laboratory Techniques in Biochemistry and Molecular Biology, Elsevier, 1991, p. 22.

[5] V. Witko-Sarsat, P. Rieu, B. Deschamps-Latscha, P. Lesavre, L. Halbwachs-Mecarelli, Neutrophils: molecules, functions and pathophysiological aspects, Lab. Investig. 80 (2000) 617-653.

[6] D. Serteyn, S. Grulke, T. Franck, A. Mouithys-Mickalad, G. Deby-Dupont, La myéloperoxydase des neutrophiles, une enzyme de défense aux capacités 
oxydantes, Ann. Med. Vet. 147 (2003) 79-93.

[7] S.J. Klebanoff, Myeloperoxidase: friend or foe, J. Leukoc. Biol. 77 (2005) 598-625.

[8] S.J. Klebanoff, A.J. Kettle, H. Rosen, C.C. Winterbourn, W.M. Nauseef, Myeloperoxidase: a front-line defender against phagocytosed microorganisms, J. Leukoc. Biol. 93 (2013) 185-198.

[9] S.W. Edwards, H.L. Nurcombe, C.A. Hart, Oxidative inactivation of myeloperoxidase released from human neutrophils, Biochem. J. 245 (1987) 925-928.

[10] J.M. Albrich, C.A. McCarthy, J.K. Hurst, Biological reactivity of hypochlorous acid: implications for microbicidal mechanisms of leukocyte myeloperoxidase, Proc. Natl. Acad. Sci. U. S. A. 78 (1981) 210-214.

[11] P.G. Furtmüller, M. Zderbauer, W. Jantschko, J. Helm, M. Bogner, C. Jakopitsch, C. Obinger, Active site structure and catalytic mechanismsofhuman peroxidases, Arch. Biochem. Biophys. 445 (2006) 199-213.

[12] J. Vlasits, C. Jakopitsch, M. Bernroitner, M. Zamocky, P.G. Furtmüller, C. Obinger, Arch. Biochem. Biophys. 500 (2010) 74-81.

[13] P.J. O'Brien, Peroxidases, Chem.-Biol. Interact. 129 (2000) 113-139.

[14] M. Paumann-Page, P.G. Furtmüller, S. Hofbauer, L.N. Paton, C. Obinger, A.J. Kettle, Inactivation of human myeloperoxidase by hydrogen peroxide, Arch. Biochem. Biophys. 539 (2013) 51-62.

[15] S. Grulke, T. Franck, M. Gangl, F. Péters, A. Salciccia, G. Deby-Dupont, D. Serteyn, Myeloperoxidase assay in plasma and peritoneal fluid of horses with gastrointestinal disease, Can. J. Vet. Res. 72 (2008) 37-42.

[16] G. de la Rebière, T. Franck, G. Beby-Dupont, A. Salciccia, S. Grulke, F. Péters, D. Serteyn, Effects of unfractionated and fractionated heparins on myeloperoxidase activity and interactions with endothelial cells: possible effects on the pathophysiology of equine laminitis, Vet. J. 178 (2008) 62-69.

[17] M.J. Davies, C.L. Hawkins, D.I. Pattison, M.D. Rees, Mammalian heme peroxidases: from molecular mechanisms to health implications, Antioxid. Redox Signal. 10 (2008) 1199-1234.

[18] E. Malle, P.G. Furtmüller, W. Sattler, C. Obinger, Myeloperoxidase: a target for new drug development? Br. J. Pharmacol. 152 (2007) 838-854.

[19] J. Soubhye, Myeloperoxidase as a target for the treatment of inflammatory syndromes: mechanisms and structure activity relationships of inhibitors, Curr. Med. Chem. 23 (2016) 3975-4008.

[20] P. Van Antwerpen, M. Prévost, K. Zouaoui-Boudjeltia, S. Babar, I. Legssyer, P. Moreau, N. Moguilevsky, M. Vanhaeverbeek, J. Ducobu, J. Nèveand, F. Dufrasne, Conception of myeloperoxidase inhibitors derived from flufenamic acid by computational docking and structure modification, Bioorg. Med. Chem. 16 (2008) $1702-1720$.

[21] I. Aldib, J. Soubhye, K. Zouaoui Boudjeltia, M. Vanhaeverbeek, A. Rousseau, P.G. Furtmüller, C. Obinger, F. Dufrasne, J. Nève, P. Van Antwerpen, M. Prévost, Evaluation of new scaffolds of myeloperoxidase inhibitors by rational design combined with high-throughput virtual screening, J. Med. Chem. 55 (2012) 7208-7218.

[22] I. Aldib, M. Gelbcke, J. Soubhye, M. Prévost, P.G. Furtmüller, C. Obinger, B. Elfving, I. Chikhalard, G. Roos, C. Delporte, G. Berger, D. Dufour, K. Zouaouiboudjeltia, J. Nève, F. Dufrasne, P. Van Antwerpen, Novel bis-arylalkylamines as myeloperoxidase inhibitors: design, synthesis and structure-activity relationship study, Eur. J. Med. Chem. 123 (2016) 746-762.

[23] J. Soubhye, M. Prévost, P. Van Antwerpen, K. Zouaoui Boudjeltia, A. Rousseau, P.G. Furtmüller, C. Obinger, M. Vanhaeverbeek, J. Ducobu, J. Nève, M. Gelbcke, F. Dufrasne, Sructure-based design synthesis an pharmacological evaluation of 3 (Aminoalkyl)-5-fluoroindoles as myeloperoxidase inhibitors, J. Med. Chem. 5 (2010) 8747-8759.

[24] R.S. Borges, J.K.L. Vale, G.A.N. Pereira, A.A.S. Veiga, J. Batista Junior, A.B.F. da Silva, An antioxidant mechanism of morphine and related derivatives, Med. Chem. Res. 25 (2016) 852-857.

[25] P. Projean, P.-E. Morin, T.M. Tu, J. Ducharme, Identification of CYP3A4 and CYP2C8 as the major cytochrome P450 s responsible for morphine $\mathrm{N}$-demethylation in human liver microsomes, Xenobiotica 33 (2003) 841-854.

[26] F. Bernheim, M.L.C. Bernheim, The oxidation in vitro of morphine by rat liver slices, J. Pharmacol. Exp. Ther. 81 (1944) 374-377.

[27] T. Todaka, T. Ishida, H. Kita, S. Narimatsu, S. Yamano, Bioactivation of morphine in human liver: isolation and identification of morphinone, a toxic metabolite, Biol. Pharm. Bull. 28 (2005) 1275-1280.

[28] I. Gülçin, S. Beydemir, H. AhmetAlici, M. Elmastas, M. EminBüyükokuroglu, In vitro antioxidant properties of morphine, Pharmacol. Res. 49 (2004) 59-66.

[29] L. Elyasi, S.H. Eftekhar-Vaghefi, S. Esmaeili-Mahani, Morphine protects SH-SY5Y human neuroblastoma cells against 6-hydroxydopamine-induced cell damage: involvement of anti-oxidant, calcium blocking and anti-apoptotic properties, Rejuv Res. 17 (2014) 255-263.

[30] T. Kanesaki, M. Saeki, Y. Ooi, M. Suematsu, K. Matsumoto, M. Sakuda, K. Saito, S. Maeda, Morphine preventsperoxynitrite-induced death of human neuroblastoma
SH-SY5Y cells through a direct scavenging action, Eur. J. Pharmacol. 372 (1999) 319-324.

[31] I.D. Welters, A. Menzebach, Y. Goumon, T.W. Langefeld, H. Teschemacher, G. Hempelmann, G.B. Stefano, Morphine suppresses complement receptor expression, pagocytosis, and respiratory burst in neutrophils by a nitric oxide and $\mu_{3}$ opiate receptor-dependent mechanism, J. Neuroimmunol. 111 (2000) 139-145.

[32] G. Minguet, T. Franck, A. Mouithys-Mickalad, J. Joris, C. Sandersen, D. Serteyn, 9th International Human Peroxidase Meeting, Cologne Conference, Sept 14-17, (2015) (Personal communication).

[33] J. Pincemail, C. Deby, A. Thirion, M. de Bruyn-Dister, R. Goutier, Human myeloperoxidase activity is inhibited in vitro by quercetin. Comparison with three related compounds, Experientia 44 (1988) 450-453.

[34] T. Momic, Z. Vujcic, V. Vasic, Kinetics of inhibition of peroxidase activity of myeloperoxidase by quercetin, In. J. Chem. Kinet. 40 (2008) 384-394.

[35] C.A. Rice-Evans, N.J. Miller, G. Paganga, Structure-antioxidant activity relationshipsof flavonoids and phenolic acids, Free Radic. Biol. Med. 20 (1996) 933-956.

[36] G.-C. Yen, P.-D. Duh, H.-L. Tsai, Antioxidant and pro-oxidant properties of ascorbic acid and gallic acid, Food Chem. 79 (2002) 307-313.

[37] T. Franck, A. Mouithys-Mickalad, T. Robert, G. Ghitti, G. Deby-Dupont, P. Neven, D. Serteyn, Differentiation between stoichiometric and anticatalytic antioxidant properties of benzoic acid analogues: a structure/redox potential relationship study, Chem. Biol. Inter. 206 (2013) 194-203.

[38] T. Franck, S. Kohnen, G. Deby-Dupont, S. Grulke, C. Deby, D. Serteyn, A specific method for measurement of equine active myeloperoxidase in biological samples and in in vitro tests, J. Vet. Diagn. Invest. 18 (2006) 326-334.

[39] D.-C. Amzoiu, A.-M. Stoian, E. Amzoiu, G. Rau, Study concerning the inhibitory activity upon myeloperoxidase of some oxicams class derivatives using the docking molecular technique, Rev. Chim. 66 (2015) 2013-2016.

[40] A. Malvezzi, R.F. Queiroz, L. de Rezende, O. Augusto, A. T.-do Amaral, MPO inhibitorsselected by virtual screening, Mol. Inf. 30 (2011) 605-613.

[41] V.A. Mashenkov, K.N. Solov'ev, G.D. Egorova, Influence of structural factors on the spectral and luminescence properties of metalloporphyrins, J. Appl. Spectrosc. (ZhurnalPrikladnoispektroskopii) 5 (1966) 152-156.

[42] M. Rubio, B.O. Roos, L. Serrano-Andrés, M. Merchan, Theoretical study of the electronic spectrum of magnesium-porphyrin, J. Chem. Phys. 110 (1999) 7202-7209.

[43] J. Colin, University Pierre et Marie Curie, Paris VI (2010), phD Thesis.

[44] B. Zelent, A.D. Kaposi, N.V. Nucci, K.A. Sharp, S.D. Dalosto, W.W. Wright, J.M. Vanderkooi, Water channel of horseradish peroxidase studied by the chargetransfer absorption band of ferric heme, J. Phys. Chem. B 108 (2004) 10317-10324.

[45] R. Re, N. Pellegrini, A. Proteggente, A. Pannala, M. Yang, C. Rice-Evans, Antioxidant activity applying and improved ABTS radical cationdecolorization assay, Free Radic. Biol. Med. 26 (1999) 1231-1237.

[46] T. Franck, S. Kohnen, S. Grulken, P. Neven, Y. Goutman, F. Peters, B. Pirotte, G. Deby-Dupont, D. Serteyn, Inhibitory effect of curcuminoids and tetrahydrocurcuminoids on equine activated neutrophils and myeloperoxidase activity, Physiol. Res. 57 (2008) 577-587.

[47] D.A. Graves, J.M. Arrigo, T.S. Foster, T.J. Baumann, R.L. Batenhorst, Relationship between plasma morphine concentrations and pharmacologic effects in postoperative patients using patient-controlled analgesia, Clin. Pharm. 4 (1985) 41-47.

[48] H.J. McQuay, D. Carroll, C.C. Faura, D.J. Gavaghan, C.W. Hand, R.A. Moore, Ora morphine in cancer pain: influences on morphine and metabolite concentration, Clin. Pharm. Therap. 48 (1990) 236-244.

[49] G. Jones, P. Willett, R.C. Glen, A.R. Leach, R. Taylor, Development and validation of a genetic algorithm for flexible docking, J. Mol. Biol. 267 (1997) 727-748.

[50] G.M. Morris, D.S. Goodsell, R.S. Halliday, R. Huey, W.E. Hart, R.K. Belew, A.J. Olson, Automated docking using a Lamarckian genetic algorithm and an empirical binding free energy function, J. Comput. Chem. 19 (1998) 1639-1662.

[51] W.L. DeLano, PyMOL, DeLanoScientific, San Carlos, CA, 2002, p. 700.

[52] A.C. Wallace, R.A. Laskowski, J.M. Thornton, Ligplot: a program to generate schematic diagrams of protein-ligand interactions, Prot. Eng. Des. Selec. 8 (1995) $127-134$

[53] Y. Shiba, T. Kinoshita, H. Chuman, Y. Taketani, E. Takeda, Y. Kato, M. Naito, K. Kawabata, A. Ishisaka, J. Terao, Y. Kawai, Flavonoids assubstrates and inhibitor of myeloperoxidase: molecular actions of aglycone and metabolites, Chem. Res. Toxicol. 21 (2008) 1600-1609.

[54] D. Maitra, F. Shaeib, I. Abdulhamid, R.M. Abdulridha, G.M. Saed, M.P. Diamond, S. Pennathur, H.M. Abu-Soud, Myeloperoxidase acts as a source of free iron during steady-state catalysis by a feedback inhibitory pathway, Free Radic. Biol. Med. 63 (2013) 90-98.

[55] L.A. Marquez, H.B. Dunford, H. Van Wart, Kinetic studies on the reaction of compound II of myeloperoxidase with ascorbic acid, J. Biol. Chem. 265 (1990) $5666-5670$. 